\title{
4 \\ Metaphysics as the First Philosophy
}

\author{
Tuomas E. Tahko
}

And there are as many parts of philosophy as there are kinds of substance, so that there must necessarily be among them a first philosophy and one which follows this. (Meta. 1004a4-6.)

\section{Introduction}

Aristotle talks about "the first philosophy" throughout Metaphysics - and it is metaphysics that Aristotle considers to be the first philosophy - but he never makes it entirely clear what first philosophy consists of. What he does make clear is that the first philosophy is not to be understood as a collection of topics that should be studied in advance of any other topics. In fact, Aristotle seems to have thought that the topics of Metaphysics are to be studied after those in Physics (Cohen 2009). In what sense could metaphysics be the first philosophy? Let me take the liberty of applying the technical jargon of contemporary metaphysics to answer: The first philosophy is an account of what is, or what it means to be, fundamental. Things that are the most fundamental are not grounded in anything more fundamental, they are ontologically independent. This does not necessarily mean that first philosophy attempts to list the most fundamental things, although this could be a part of the discipline. Rather, the study of fundamentality focuses on giving an account of what it is for something to be fundamental. So, first philosophy studies a certain type of being - the fundamental type, and it may also involve an account of which (kind of) things are, or could be, fundamental.

It is plausibly the task of "the second philosophy", i.e. physics, to determine which things are in fact fundamental, although, as we will see, this is not possible without a previous account of what fundamentality is. For instance, explaining the view according to which 
elementary particles are fundamental requires a previous understanding of what it would mean for them to be fundamental. Of course, this is not at all how Aristotle would have put it, but many contemporary metaphysicians working on the currently popular topics of fundamentality, grounding, and ontological dependence explicitly refer to Aristotle as the ideological source of these notions (e.g. Schaffer 2009, Lowe 2011, Fine 2012, Koslicki 2012a, and Tahko 2012). In this chapter, I will explore the connection between Aristotle's conception of metaphysics as the first philosophy and the contemporary "neo-Aristotelian" accounts of the nature of metaphysics. However, I will suggest that it is in terms of the notion of essence rather than fundamentality, grounding, or ontological independence that we can best characterize the idea of first philosophy, albeit there are obvious points of connection between these notions. Metaphysics, it turns out, is the science of essence.

I will first outline the Aristotelian roots of first philosophy in section 2, presenting an overview of some important notions, such as being, substance, and essence. In Section 3, I will discuss some of the most influential neo-Aristotelian accounts with special attention to the manner in which they interpret the idea of first philosophy and priority. This will involve a brief analysis of the currently topical notions of fundamentality, grounding, and ontological dependence, all of which have been used to illustrate the (Aristotelian) notion of priority. Section 4 focuses on my own suggestion regarding the interpretation of first philosophy and metaphysics as the science of essence. Here, I will partly build on the work of E. J. Lowe and Kit Fine as well as my previous work on essence. I suggest that, despite some exegetical issues regarding Aristotle's own views about essence, we should consider essence to precede existence ontologically, that is, the essence of a thing is not dependent on the existence of the thing - all kinds of possible things have an essence. I conclude with a case study from theoretical physics, the case of the Higgs boson. This case study illustrates how the suggested understanding of essence ties in with natural science and provides some evidence of the ontological and epistemic priority of essence. However, I also wish to analyze the relationship between metaphysics and natural science, so the case study serves multiple purposes.

\section{First philosophy in Aristotle}

The role of first philosophy in Aristotle is certainly more complicated than I have acknowledged so far. Indeed, I do not think that it can be sufficiently explicated in terms of fundamentality, ground, or ontological 
dependence - even if these popular notions do have Aristotelian roots and are crucial for our understanding of metaphysics more generally. Rather, I think it is in terms of essence that we should understand the idea of the first philosophy, as I will explain in what follows. But let us first examine Aristotle's own view. This will turn out to be rather more challenging than one might think, because there are relatively few methodological passages in Aristotle, and in his Metaphysics in particular. There is, however, no doubt that it is the "science of being qua being" that Aristotle considers to be the first philosophy. The question, then, is how we should understand this rather obscure expression. In this section, I will analyze the idea of "being qua being", although my discussion should not be regarded as Aristotle exegesis. In particular, I am interested in explicating a modern understanding of first philosophy, with special attention to the methodological challenges that first philosophy - as a science of being qua being - will face. ${ }^{1}$

So, what is the science of being qua being? First, it should be noted that it is not "being qua being" that is the subject of first philosophy - the subject is "being", which is studied "qua being" (being as it is in itself) (Cohen 2009). This is to contrast first philosophy with (natural) science, which, of course, also studies being, but not as it is in itself, but rather with a particular end or purpose in mind. This particular end could be, for instance, countability, which falls within the mathematical sciences, whereas metaphysics studies all kinds of being on a much more general level. It is in Metaphysics $\mathrm{G}$ where Aristotle introduces being qua being, but we also find some detailed discussion in Metaphysics K. Perhaps the most illustrative passage for our current purposes comes from Metaphysics E:

One might indeed raise the question whether first philosophy is universal, or deals with one genus, i.e. some one kind of being; for not even the mathematical sciences are all alike in this respect, geometry and astronomy deal with a certain particular kind of thing, while universal mathematics applies alike to all. We answer that if there is no substance other than those which are formed by nature, natural science will be the first science; but if there is an immovable substance, the science of this must be prior and must be first philosophy, and universal in this way, because it is first. And it will belong to this to consider being qua being - both what it is and the attributes which belong to it qua being. (Meta. 1026a25-33.)

Here, Aristotle tells us that it is "substance" that first philosophy studies. Indeed, moments later he specifies that the question of being is simply the 
question of substance (Meta.1028b3-8). It is beyond the scope of this essay to explicate the Aristotelian notion of "substance" in any detail, but it is important to understand that substances are ontologically prior - this is a topic that I will return to in the next section. ${ }^{2}$ Aristotle lists a number of different options for what it is to be a substance; the primary candidates are essence, universal, genus, and subject. I will focus on the first one, which I find the most interesting. The reason for this choice is mainly that I believe there to be good reasons to think that understanding substances as essences is the best way of accommodating the Aristotelian idea of metaphysics as the first philosophy in contemporary metaphysics. Let me first sketch Aristotle's own case for understanding substances as essences - he presents it in Metaphysics Z.4-12.

Regarding essence, Aristotle says: "The essence of each thing is what it is said to be in virtue of itself" (Meta. 1029b14). Do not be misled by the "what it is said" in this passage, for it is quite clear that Aristotle does not consider essences to be a matter of convention - compare this with the distinction between a nominal and a real definition, or essence, also familiar from Locke (cf. Lowe 2011). As Bolton $(1976,524)$ puts it, "A nominal definition signifies [...] the same thing that one type of real definition displays [...]; and that is an essence." Bolton (ibid., 515) also suggests that, for Aristotle, knowledge of existence typically precedes knowledge of essence, but I consider this to be debatable. Bolton's case is based on his reading of the Posterior Analytics (especially 93a16-24). For instance, Aristotle discusses whether someone could know what a goatstag is, but denies that this is possible - even though one may know what the name signifies - since goatstags do not exist (92b4-8). However, as Demoss and Devereux (1988) have pointed out, there are passages even in the Posterior Analytics that suggest the issue to be more complicated. In particular, Aristotle says that in grasping that a thing is, we also have "some hold on what it is" (93a25-28). Demoss and Deveraux $(1988,150)$ take this passage to be evidence to the effect that nominal definitions refer to underlying essences. This seems plausible, as if we set aside the interpretational issues regarding the Posterior Analytics and look at what Aristotle says about essence in the Metaphysics, we can find a potential explanation for the conflicting interpretations.

The explanation, I conjecture, is that Aristotle holds only species to have essences (1030a11-17); and more importantly, that species are eternal (e.g. Generation of Animals, 731b24-732a1). ${ }^{3}$ We can now see that, for Aristotle, there could never be an essence of a non-existent thing, such as a goatstag, for Aristotle thinks that there could be no such thing. Therefore, if we were to share the Aristotelian conception of species, we 
would indeed have to agree with him that there is no goatstag essence. Surely, only things that could possibly exist can have essences, and since there are no actual goatstags, Aristotle regards them to be impossible in this sense. Aristotle does not use these exact terms, but we can perhaps take Aristotle's notion of actuality to correspond with what I am here calling existence. Similarly, my use of possibility roughly corresponds with Aristotle's potentiality. Accordingly, we can formulate the idea at hand as follows: actuality precedes potentiality. It follows that this peculiar doctrine may be an artifact of the Aristotelian conception of species, although this brief analysis is hardly conclusive.

It is reasonable to assume that the Aristotelian conception of species is not widely supported by contemporary philosophers. Hence, for the purposes of adopting the central Aristotelian idea of metaphysics as the first philosophy, I suggest a deviation from the Aristotelian conception of species rather than the idea that essence precedes existence, which I believe to have independent appeal. In any case, the purpose of this essay is not exegetical - I merely hope to have established that there may be room for an interpretation of Aristotle which does not rule out the possibility of essence preceding existence.

In the next section, I will begin to establish a link between contemporary analytic metaphysics (with Aristotelian influences) and the Aristotelian idea of metaphysics as the first philosophy.

\section{Fundamentality, grounding, ontological dependence, and essence}

The four notions in the title of this section are currently receiving an abundance of interest in analytic metaphysics. They all have roots in Aristotle, and this is often explicitly acknowledged in the literature. For instance, here is Jonathan Schaffer on grounding and fundamentality:

I will argue for the revival of a more traditional Aristotelian view, on which metaphysics is about what grounds what. Metaphysics so revived does not bother asking whether properties, meanings, and numbers exist. Of course they do! The question is whether or not they are fundamental. (Schaffer 2009, 347.)

Schaffer is firmly of the opinion that for Aristotle, metaphysics is about what is fundamental in the sense of not being grounded in anything else. It is natural to think of first philosophy as the discipline which studies the ultimate ground of reality. As we saw in the previous section, 
the Aristotelian notion of substance would appear to be fundamental in this sense. Fundamentality and grounding are interrelated notions, and they can both be further explicated in terms of ontological dependence. ${ }^{4}$ However, the latter comes in a number of varieties, and we should be quite careful in our analysis of fundamentality and grounding with the help of ontological dependence. In particular, although some varieties of ontological dependence can be explicated in modal or existential terms, these are not sufficiently fine-grained in all cases, especially if we hope to make sense of Aristotelian priority. As Koslicki (2012b) observes, Aristotle's conception of dependence, at least in the Categories, is often described in modal and existential terms, i.e. all things necessarily depend for their existence on the existence of primary substances. But this may not be the most plausible manner to interpret Aristotle's views on ontological dependence. Indeed, Aristotle himself was not unaware of the various ways that ontological dependence could manifest itself (Corkum 2008, 75). So, although Aristotle can sometimes be seen to use a modal characterization of ontological dependence (for instance in Categories 14a30-35), this does not mean that such a characterization is always correct. In particular, it gives implausible results when applied to essence and existence. Corkum's recent account is helpful here: ${ }^{5}$

Aristotle is generally less concerned with the question of what things exist than we might expect. His ontological concerns are typically with such questions as, given the things which we call beings, in virtue of what does each such thing have claim to this ontological status? For example, this is Aristotle's concern with respect to mathematical objects: the philosophical question is not whether such things exist but how they do: see Meta. 1076a36-37. (2008, 76.)

This type of reading has received plenty of support recently. For instance, Peramatzis (2011, $203 \mathrm{ff}$.) also argues that a non-existential reading of Aristotelian ontological priority is more plausible, and Koslicki (2012b) abandons the existential reading at the outset. Peramatzis further points out that the modal formulation of Aristotelian ontological priority can be grounded in the non-modal, essentialist characterization, i.e. the "how" question described by Corkum. This can be considered to further support the idea that essence precedes existence, as suggested in the previous section.

How does the notion of essence tie in with Aristotelian priority? According to Ferejohn $(2003,327)$, one of Aristotle's central concerns in the Metaphysics is to determine what the fundamental entities are, 
or how they are. Ontologically independent, fundamental entities are (primary) substances - of which forms are the key example. Here, we once again encounter essences, for Aristotle says that "By form I mean the essence of each thing and its primary substance" (1032b1-2). ${ }^{6}$ On a related note, Tierney $(2004,7-8)$ specifies that the ti esti ("what it is") of a substance, i.e. the essence or form of a substance, is a metaphysical primitive. The significance of this observation lies in the fact that the Aristotelian notion of essence cannot be defined in terms of other concepts or in virtue of the necessary features of a thing (Tierney 2004, 8, fn. 23). Finally, I draw on Yu (2003), who asserts that "The identity of form and essence unambiguously shows that the contest for the title of primary substance is not between form (which is one subdivision of subject) and essence" (p. 97).

Essences have the status of primary substances in Aristotle and are hence a natural candidate for the subject matter of first philosophy. But note that essences are not the ultimate ground of reality in the sense that Schaffer talks about ultimate ground. Essences should be understood as answering the ti esti question, which may include an account of what grounds the existence of an entity, but essences themselves are primitive for Aristotle and are hence not grounded in anything else. In one sense, essences are certainly fundamental, but they are not fundamental entities; rather, they are a part of Aristotle's fundamental ideology, and in this respect the notion of fundamentality applicable to Aristotle may be closer to Sider's ideological fundamentality: instead of a mereological "bottom level", as with Schaffer's entity-fundamentality, we are interested in the ideological "bottom level" of Aristotle's ontology (cf. Sider 2011: vii). The notion of ideology has a Quinean origin; it concerns a theory's choice of primitive notions. ${ }^{7}$

There is a continuity between the Aristotelian, primitive non-modal conception of essence and the neo-Aristotelian characterization of essence popularized in particular by Kit Fine (e.g. 1994, 1995a, 1995b, 1995c), although there are surely some differences between Fine's and Aristotle's accounts. I will not concern myself with an analysis of these differences, for they have already been discussed extensively (e.g. Klima 2002, Peramatzis 2011, Koslicki 2012a, Corkum forthcoming). All I wish to conclude from this section is that it is legitimate to understand Aristotelian priority in terms of essence. This analysis is certainly related to those of Schaffer, Fine, Koslicki, and many others, but I lack the space to discuss their accounts in detail. Rather, I will proceed to present my own account of metaphysics as the first philosophy, drawing on the previous discussions and Lowe's work in particular. 


\section{The science of essence as the first philosophy}

We now have the beginnings of an account of essence as the subject matter of first philosophy, so it is time to explicate the study of essence itself. The starting point of my proposed conception of essence is the idea that essence precedes existence. The picture that I will present is inspired by Aristotle - it might be called neo-Aristotelian - but the goal is not to be faithful to Aristotle. I hope to present what I believe to be the correct account of the role of essence in metaphysics and, as it turns out, this also provides a natural understanding of metaphysics as the first philosophy. Of contemporary accounts, Lowe's (who draws extensively on Fine in this connection) is perhaps closest to the one that I am about to present. Indeed, he coins the phrase "essence precedes existence" as follows:

[I]n general, essence precedes existence. And by this I mean that the former precedes the latter both ontologically and epistemically. That is to say, on the one hand, I mean that it is a precondition of something's existing that its essence - along with the essences of other existing things - does not preclude its existence. And, on the other hand [...] I mean that we can in general know the essence of something $X$ antecedently to knowing whether or not $X$ exists. Otherwise, it seems to me, we could never find out that something exists. For how could we find out that something, $X$, exists before knowing what $X$ is - before knowing, that is, what it is whose existence we have supposedly discovered. (Lowe 2008, 40.)

This conception of essence has a number of important ramifications, which ought to be stated explicitly. Firstly, essences themselves are not entities. The importance of noting this is highlighted by another central assumption, namely that all entities must have an essence. This is just to say that an entity must have a determinable set of existence, identity and persistence conditions, whether or not we know these conditions in full. Now, if essences themselves were entities, this would produce an infinite regress of a rather vicious sort, since essences themselves, being entities, would have to have essences, and so on. So, if a thing exists, it must have an essence, but to have an essence is simply to have a real definition. In fact, since I think that non-existent entities can have essences, we can say even more, namely, that every metaphysically possible entity must have an essence. I should also mention that I do not think that it makes sense to talk about the essence of something precluding its 
existence. Here is why: for a thing to be metaphysically possible, it must be possible that it could have existed. A thing whose essence precludes its (possible) existence is contradictory - I take it that a set of existence conditions which precludes existence altogether is impossible. Thus, goatstags, insofar as they could exist, also have essences. In many cases, we also know the essences of non-existent things.

A brief note about the connection between my understanding of essence and grounding is also in order. The essence of a thing is not meant to refer to the ultimate or fundamental ground of being of a thing. Rather, it just refers to being, i.e. what it is, or would be, for a thing to exist. The existence of a given thing can and will, of course, depend on the existence of other things, unless it is ontologically independent (and at least on one view, these facts about existential dependence may be grounded in the essence of the thing). ${ }^{8}$ But essence itself should not be considered as the ultimate or fundamental ground of the being of the entity whose essence it is. I prefer to think of essence more as a statement of what the being of the entity consists in; its existence, identity, and persistence conditions. Depending on one's view, it may or may not be part of the essence of a thing that its existence is grounded in the existence of some fundamental things, that is, whether or not facts about what grounds what are themselves grounded in the essences of things. We do not need to settle these questions here though.

Lowe's account of essence is probably closest to my own, but there are some important points of difference between our views. The most crucial of these differences involves the relationship between essence and modality. I agree with Lowe and Fine on the ontological order of explanation between essence and modality. So do Aristotle and the majority of the commentators I have referred to above. But I consider the epistemic order of explanation to be debatable. Let me elaborate.

The ontological relationship between essence and modality that I subscribe to suggests that not all necessary truths about a given object $X$ are essential truths about $X$, but all necessary truths are grounded in essential truths (about something or other). This implies that essential truths about $X$ are a proper subset of the necessary truths about $X$, but even those necessary truths about $X$ that are not essential truths about $X$ are nevertheless essential truths about something. We can illustrate this with Fine's (1994) classic example of Socrates and his singleton: Socrates is necessarily a member of singleton Socrates, but this does not appear to be essential for Socrates. Rather, it is part of the essence of sets that they have their members essentially, and hence true in virtue of the nature of sets that Socrates belongs to singleton Socrates. This is the type 
of confusion about essentiality and necessity that Fine is attempting to weed out. Moreover, according to this view, essence is ontologically prior to modality in the sense that essential truths are more fundamental than modal truths. Finally, it is also important to note that on this view, we should not reduce essence to de re modal properties.

On the epistemic side, things are murkier. Lowe (e.g. forthcoming) is of the opinion that our epistemic access to essence is direct and $a$ priori, and generally within everyone's capabilities. However, some (e.g. Oderberg 2007, 2011) would contest this and favor a posteriori access to essence; this approach is commonly associated with the idea that science discovers essences. There are good reasons to think that Aristotle himself would be more amenable to the latter line, although I should note that Lowe makes no claim to the effect that his view is the Aristotelian one. Indeed, even the essentialist tradition due to the work of Kripke and Putnam is perhaps more faithful to Aristotle in this regard. Be that as it may, I side with Lowe, at least to the extent that the science of essence must be an a priori discipline. Lowe (forthcoming) claims that the a posteriori essentialists are mistaken in their claim that we "discover" essences empirically. He considers the Aristotelian real definition, i.e. essence, to provide a type of formula for a thing or a kind of thing, which may or may not manifest in the actual world.

Where I differ from Lowe is on the nature of our a priori access to essence, as I consider it to be indirect. Specifically, I hold that we have direct a priori access to modal truths rather than essentialist truths. Further, since I take all modal truths to be grounded in essentialist truths, there is a necessary link between modal truths and essentialist truths. So, compared to Lowe's approach, I propose to reverse the epistemic order of essence and modality. I develop this account in detail elsewhere (Tahko ms. A); here, I wish to focus on a caveat for any account according to which modality is epistemically prior to essence. The caveat is that we must have some means to determine which of the necessary truths concerning an object are essentialist truths about that object. As the formulation of the relationship between essence and modality proposed above suggests, essentialist truths are a proper subset of necessary truths, and we need some criteria to identify this subset. Furthermore, the criteria that we use to determine this should not assume previous knowledge of essentialist facts, for otherwise the view would collapse into pure a priori essentialism. ${ }^{9}$ This is, of course, familiar already from Aristotle, who holds that there are necessary, but inessential, properties called propria. Propria do not tell us what a thing is, i.e. they do not answer the ti esti question, or Corkum's "how" question (that is, how a 
thing exists). ${ }^{10}$ However, it appears that for Aristotle this problem does not arise in a similar manner, for it is always (empirical) science that determines the real definition. I will offer the beginnings of a solution to this problem - call it "the problem of propria" - in what follows.

My solution begins with the assumption that we have a priori access to metaphysical possibility, and it is via this modal knowledge that we access the essences of all possible kinds of entities, whether they exist in the actual world or not. This process is empirically indefeasible in the sense that it only concerns possibilities. It is an empirical question, which of these possibilities correspond with the actual world. For instance, provided that Euclidean geometry is consistent, it is one possible scenario of what the actual geometry of the world could be like, among the other alternative geometries. ${ }^{11}$ There is still a modal fact at play here, and it must also be grounded in essence. Since the picture at hand accommodates the essences of non-existing things as well, there is nothing strange about there being essentialist facts that ground non-actual geometries.

We can use Aristotle's own example - that of a goatstag - to illustrate the problem of propria. As we saw in Section 2, despite Aristotle's initial skepticism about anyone being able to know what a goatstag is, there are some suggestions in the Posterior Analytics to the effect that just being able to use the nominal definition of a goatstag entails there being some previous hold on what the thing in question is. I consider it plausible that this previous understanding consists of modal knowledge. Specifically, we are interested in the set of essential properties that could manifest in a thing like goatstag, were such a thing to exist. Of course, not just any combination of properties is possible, for some of these properties are mutually exclusive (e.g. round and square). We must first rule out the impossible combinations of properties, which delimit the space of possible kinds of objects to those that at least could have existed. It seems that even Aristotle himself considers goatstags to be possible in this sense, although we saw that because Aristotelian species are eternal, he would consider all things that do not exist to be impossible. Yet, if we can know what the name "goatstag" signifies, as Aristotle acknowledges, then it seems that at least some grasp of what goatstags are, or would be, is required. This is certainly the conclusion that Lowe's analysis suggests:

To know something's essence is not to be acquainted with some further thing of a special kind, but simply to understand what exactly that thing is. This, indeed, is why knowledge of essence is possible, for 
it is a product simply of understanding - not of empirical observation, much less of some mysterious kind of quasiperceptual acquaintance with esoteric entities of any sort. And, on pain of incoherence, we cannot deny that we understand what at least some things are, and thereby know their essences. (Lowe 2008: 39.)

According to this analysis, some knowledge of the essence of a goatstag is needed in order to even understand what is being said when one hears someone talking about a goatstag. Lowe, (forthcoming, [17-18]) in fact, suggests that understanding what a thing is just means understanding the proposition that expresses the real definition of the thing. He does not say all that much about what propositions expressing real definitions are like, but it is not implausible that they list the existence, identity, and persistence conditions of things. Of course, in some cases, the existence conditions may not be satisfied in actuality - because the thing may not exist - but listing these conditions is a crucial part of expressing the essence of a thing.

The link between grasping the essence of a thing with understanding what a thing is, proposed by Lowe, rests on the idea that some previous knowledge of essence is required in order to comprehendingly talk about, say, goatstags. However, it does appear that there must be something more to essence than just the bundle of the existence, identity and persistence conditions of things, for how are we supposed to know which object a given set of such conditions is associated with?

Indeed, this the heart of the problem of propria. Specifically, what is it about a set of necessary properties that makes it the essence of a thing, when we know that there are propria, i.e. necessary properties which are not essential? A given member of a natural kind must have a certain set of essential properties to qualify as a member of that kind, but what determines the essence of the kind? Oderberg $(2011,97)$ introduces a unifying a priori principle, unique to each kind, in order to establish this link, but I have my doubts about this move. If each object is associated with a unique unifying principle, then the unifying principle itself is starting to look very much like the essence, and it is not at all clear to me that this helps in addressing the epistemic problem. Let me use another example to illustrate the problem and sketch a potential solution.

\section{Case study: the Higgs boson}

If you have not heard the news yet, the discovery of the Higgs boson was announced on July 4th 2012 by two independent teams working at 
CERN in Switzerland. More information regarding the discovery is to be expected in the coming months and years, but at the time of writing, the situation is as follows: ${ }^{12}$

- A new boson has been discovered in the mass range 125-126 GeV.

- This falls within the expected mass range of the Higgs boson.

- The Higgs boson was originally postulated in the 1960s to help to explain how particles get their mass.

- Actually, it is the Higgs field that would do this.

- Physicists knew already before the discovery that there is something like a Higgs field or fields that would serve this explanatory purpose.

- The only way to study this field, or fields, is to study the Higgs boson(s) (which is/are not directly observable either).

- The Standard Model of Quantum Mechanics predicts one type of Higgs, the Standard Model Higgs, but the discovered particle might not be the Standard Model Higgs; this depends on the particle's properties, such as spin.

In short, physicists knew that there must be something like the Higgs field which is responsible for the mass of things like $\mathrm{W}$ and $\mathrm{Z}$ bosons elementary particles that had already been discovered. Physicists wish to study the properties of this field, which can be done by finding and studying the corresponding Higgs boson. The Higgs field might not be elementary; it could be composed of several other fields, each of which would have a corresponding Higgs boson. Many of the details will not matter for our purposes, but a few things are crucial. In particular, we know of a number of possible combinations of particles and fields that would explain our current empirical data.

What I wish to focus on is the relevance of the existence of the Higgs boson(s), while keeping in mind that the discovered particle might not be the Standard Model Higgs. We know that whatever the arrangement of elementary fields and particles is, they manifest themselves in such a way that we observe massive particles like $\mathrm{W}$ and $\mathrm{Z}$ bosons. Hence, we are primarily interested in an explanation for previous data, that is, we want to understand the mechanism which is responsible for the emergence of massive particles (i.e. the Higgs mechanism). To this end, it makes little difference whether the Higgs boson exists. The experiments at the Large Hadron Collider at CERN are designed to reveal us something more about the nature of the Higgs field or fields, and we already know of the existence of something like the Higgs field(s). Now it seems that at least one type of Higgs boson has been discovered, but 
at the time of writing it is unclear what its properties are. We know that it is a boson, and hence has an integer spin, but only a scalar boson (i.e. a boson with a spin of zero) could serve the postulated role in the Standard Model. All this was clear before any confirmation of the existence of the Higgs boson(s).

It is not difficult to see where I am going with this example. Firstly, I consider it a real-life example of how knowledge of essence can precede knowledge of existence. But it is more than that, for there is also an implicit solution to the problem of propria here. Specifically, how do we know that theoretical physicists are talking about the same thing when they debate the properties and the existence of the Higgs boson(s)? That is, how do we know that the properties are essential to that kind of thing instead of some other kind of thing, especially if we do not even know whether there is only a single Higgs, or several? There is certainly some common ground between the disputants, such as the Standard Model, but that is hardly sufficient to ensure that they are indeed talking about the same thing. In fact, I do not think that it is even necessary. Here is why: there are numerous candidate essences that are able to fulfill the explanatory role that the Higgs boson(s) play, and not all of them conform to the Standard Model. By the time you read this, we may already know whether the recently discovered boson is the Standard Model Higgs, but at the time of writing all these options were still open.

We have a reasonably good idea as to what would explain the empirical data that we currently have. Among other things, we have already observed $\mathrm{W}$ and $\mathrm{Z}$ bosons and other massive particles. It turns out that unless something like the Higgs field(s) is postulated, the Standard Model will have to be abandoned (at least in part). So, the need to postulate the Higgs field(s) stems from the conviction that the Standard Model must be saved. But the Higgs field(s) cannot be observed directly, nor can the Higgs boson(s): we can only infer its/their existence from decay products. So, we looked for evidence of the Higgs boson(s) via their decay products, and the existence of the Higgs entails the existence of the corresponding field(s). However, I suggest that it is the explanation - not the existence of something or other - that guarantees a common ground between physicists working on the Higgs.

When the search for the Higgs began, its possible mass range was fairly wide. The LHC ruled out chunks of it little by little, finally arriving at 125-126 GeV. But all of the specific masses in the original range were possible (essential) properties of the kind of thing that we were looking for. I venture to suggest that we must have known what kind of thing would explain the data before we were able to systematically look for 
evidence for its existence. It could have turned out that it is a merely possible kind of thing, and it could still turn out that the Higgs field is not elementary and instead consists of a number of other fields. But even in this case, we had a previous grasp of the essences of the other possible kinds of things that would have explained the data, though no such things exist. So, the explanation we are looking for is connected with the kind(s) of thing(s) that occupies (or occupy) an appropriate explanatory role.

How does this help to solve the problem of propria? Well, since our epistemic access is to possible rather than actual essences, a crucial part of our inquiry is listing the different possible combinations of (logically compatible) necessary features which may or may not be unified into a genuine, actual kind. Ultimately, it is the task of empirical science to determine which of the candidate essences that we conjecture are actual essences, that is, which combinations of essential features make up genuine kinds. This is exactly what we see in the case of the Higgs boson(s): we had a list of candidate essences compatible with current empirical data, consisting of sets of necessary properties. What unifies these sets of necessary properties into kind essences is the explanatory role that they play in the context of the broader theory. The role of the Higgs field(s) is to give particles their mass, regardless of whether the Higgs field is elementary and whether there is more than one Higgs boson. This enables us to determine the candidate essences, i.e. the different combinations of properties that would enable the role that the Higgs field(s) play. The genuine, actual essences must be determined with the help of empirical evidence. Notice that I do not say discovered, because the role of the empirical work is merely to confirm which of the candidate essences are genuine. Hence, the problem of propria will ultimately be addressed by empirical science, but not without a prior study of the candidate essences. Importantly, this process is fallibilistic: We can only make an educated guess about which essences are genuine. Science determines whether we guessed correctly, but science is, of course, subject to revision as well. The existence of the Higgs boson has now been confirmed to 5.0 sigma significance, i.e. to a level of certainty up to five standard deviations. In statistical terms, this means a probability of less than one in a million that the observed phenomenon is produced by something else than the Higgs, namely statistical fluctuation. But, if further empirical information emerges, we can always revise the picture.

In sum, our epistemic access to essence is a piecemeal, complex matter, yet a necessary precursor of philosophical and scientific knowledge. 


\section{Conclusion}

I trust that the reader has not lost sight of our original topic. The understanding of metaphysics as the first philosophy that I have presented rests on the idea that metaphysics is the science of essence. In Section 2, we saw that it is not unreasonable to attribute this view to Aristotle. Contemporary metaphysicians have different views about how to understand the relationship between essence and the now-popular topics of fundamentality, grounding, and ontological dependence, discussed in Section 3. I attempted to demonstrate that all of these notions can be tied to Aristotle and especially his discussion of priority, even if the contemporary discussion is not entirely continuous with Aristotle. In any case, the notion of essence has a central role here. What the science of essence amounts to is somewhat more controversial. I have only been able to provide a glimpse into the topic here, but I hope that this has been sufficient to motivate further research into this emerging field. I side with Lowe in that I consider essence to precede existence (ontologically), and in Section 4 I attempted to defend this idea, which may or may not be faithful to Aristotle. I make no exegetical claims in this regard, but as we saw, there may be some reasons to think that this idea can be reconciled with the passages in Posterior Analytics that are seemingly opposed to it. Finally, in Section 5, I took an example from theoretical physics to illustrate the science of essence as I understand it. We saw that even though the study of essence takes epistemic priority, the picture would not be complete without empirical input. This I believe to be a point in accordance with the Aristotelian line, as it is clear that natural science plays an important part in Aristotle's metaphysics.

One might perhaps object that the label "first philosophy" is not entirely accurate for the account I have presented, for metaphysics and natural science could be considered to be parallel, or to complement each other. But this would be to ignore the Aristotelian roots of the notion of "first philosophy", which, as I have demonstrated, are amenable to such an understanding. What makes metaphysics the first philosophy is its ontological as well as epistemic priority over natural science rather than complete independence of empirical science.

\section{Notes}

I would like to thank Tommy Kivatinos, Kathrin Koslicki, and Mika Perälä for comments and discussion regarding many central topics of this essay. 
1. For some discussion of these methodological challenges with actual Aristotle exegesis, see Ferejohn (2003).

2. See, for instance, Witt (1989), Scaltsas (1994), and Koslicki (this volume) for more discussion of the notion of substance.

3. See Bodnar (2012), and also Witt (1989, 144ff.) and Cohen (2009). I would like to thank Kathrin Koslicki for useful discussions regarding this issue. Some further support for my reading can be found from David Charles (2000), who discusses Aristotle's conception of species in much more detail (e.g. 2000, 25).

4. See the essays in Correia and Schnieder (2012) for a comprehensive overview of the topic.

5. However, see Corkum (forthcoming) for some more hesitant remarks on Aristotle's views regarding existence.

6. See also Yu (2003, 105ff.) and Wedin (2000, 197ff.) on the identity of form and essence.

7. I consider there to be a significant chasm between Aristotelianism and Quineanism, but in this case the Quinean notion of ideology serves an illustrative purpose.

8. For further discussion, see Dasgupta (ms.).

9. This is related to the problem of unifying a set of essential properties into, say, a kind essence: there should be something to hold a set of essential properties together in order to ensure that the essential properties of a given kind are always featured in the members of that kind. Oderberg $(2011,90)$ calls this "the unity problem", but sometimes it is also called "the problem of complex essences" (e.g. Dumsday 2010). Since my emphasis is slightly different, I will adopt another name for the (interrelated) problem(s): "the problem of propria".

10. See also Corkum (forthcoming, [17]), as well as Fine (1994) and Koslicki (2012a).

11. See Tahko (ms. B) for further discussion.

12. For a more comprehensive survey and future updates, see Matt Strassler's "Higgs FAQ", URL = <http://profmattstrassler.com/articles-and-posts/the-higgsparticle/360-2/>.

\section{References}

J. Barnes (ed.) 1984. The Complete Works of Aristotle, The Revised Oxford Translation (Princeton: Princeton University Press).

I. Bodnar. 2012. "Aristotle's Natural Philosophy," The Stanford Encyclopedia of Philosophy (Spring 2012 Edition), Edward N. Zalta (ed.) URL = http://plato.stanford.edu/archives/spr2012/entries/aristotle-natphil/.

R. Bolton. 1976. "Essentialism and Semantic Theory in Aristotle," The Philosophical Review 85 (4): 514-44.

D. Charles. 2000. Aristotle on Meaning and Essence (Oxford: Clarendon Press).

S. M. Cohen (2009) "Aristotle's Metaphysics," The Stanford Encyclopedia of Philosophy (Spring 2009 Edition), Edward N. Zalta (ed.) URL = http://plato.stanford.edu/archives/spr2009/entries/aristotle-metaphysics/.

P. Corkum. 2008. "Aristotle on Ontological Dependence," Phronesis 53: 65-92. 
forthcoming. "Substance and Independence in Aristotle," in B. Schnieder,

A. Steinberg and M. Hoeltje (eds), Ontological Dependence, Supervenience, and Response-Dependence, Basic Philosophical Concepts Series (Munich: Philosophia Verlag).

F. Correia and B. Schnieder. (eds.) 2012. Metaphysical Grounding (Cambridge: Cambridge University Press).

S. Dasgupta (ms.) "The Status of Ground," draft of November 2011.

D. Demoss and D. Devereux. 1988. "Essence, Existence, and Nominal Definition in Aristotle's 'Posterior Analytics' II 8-10", Phronesis 33: 133-54.

T. Dumsday. 2010. "Natural Kinds and the Problem of Complex Essences," Australasian Journal of Philosophy 88 (4): 619-34.

M.T. Ferejohn. 2003. "Logical and Physical Inquiries in Aristotle's Metaphysics," The Modern Schoolman LXXX, 325-50.

K. Fine. 1994. "Essence and Modality," Philosophical Perspectives 8 (Logic and Language), 1-16. 1995a. "Ontological Dependence," Proceedings of the Aristotelian Society 95: 269-90.

1995b. "Senses of Essence," in W. Sinnott-Armstrong, D. Raffman and N. Asher (eds), Modality, Morality, and Belief, Essays in Honor of Ruth Barcan Marcus (Cambridge: Cambridge University Press), pp. 53-73.

1995c. "The Logic of Essence," Journal of Philosophical Logic 24: 241-73. 2012. "What is Metaphysics?" in T. E. Tahko (ed.) Contemporary Aristotelian Metaphysics (Cambridge: Cambridge University Press), pp. 8-25.

G. Klima. 2002. "Contemporary 'Essentialism' vs. Aristotelian Essentialism" in J. Haldane (ed.) Mind, Metaphysics, and Value in the Thomistic and Analytical Traditions (Notre Dame, IN: Notre Dame University Press), pp. 175-94.

K. Koslicki. 2012a. "Essence, Necessity and Explanation" in T. E. Tahko (ed.) Contemporary Aristotelian Metaphysics (Cambridge: Cambridge University Press), pp. 187-206.

2012b. "Varieties of Ontological Dependence" in F. Correia and B. Schnieder (eds), Metaphysical Grounding (Cambridge: Cambridge University Press). this volume. "Substance, Independence and Unity."

E. J. Lowe. 2008. "Two Notions of Being: Entity and Essence," Royal Institute of Philosophy Supplements 83 (62): 23-48.

2011. "Locke on Real Essence and Water as a Natural Kind: A Qualified

Defence," Aristotelian Society Supplementary Volume 85 (1), 1-19. forthcoming. "Grasp of Essences versus Intuitions: An Unequal Contest," in

T. Booth and D. Rowbottom (eds), Intuitions (Oxford: Oxford University Press).

D. Oderberg. 2007. Real Essentialism (London and New York: Routledge). 2011. "Essence and Properties," Erkenntnis 75: 85-111.

M. Peramatzis. 2011. Priority in Aristotle's Metaphysics (Oxford: Oxford University Press).

T. Scaltsas. 1994. Substances and Universals in Aristotle's "Metaphysics" (Ithaca and London: Cornell University Press).

J. Schaffer. 2009. "On What Grounds What," in D. Manley, D. J. Chalmers, and R. Wasserman (eds), Metametaphysics: New Essays on the Foundations of Ontology (Oxford University Press), pp. 347-83.

T. Sider. 2011. Writing the Book of the World (Oxford: Oxford University Press). 
T. E. Tahko. 2012. "In Defence of Aristotelian Metaphysics," in T. E. Tahko (ed.) Contemporary Aristotelian Metaphysics (Cambridge: Cambridge University Press), pp. 26-43.

(ms. A) "The Epistemology of Essence," URL = http://www.ttahko.net/papers/ epistofessence.pdf.

(ms. B) "Euclidean Geometry and the A Priori," URL = http://www.ttahko.net/ papers/euclid.pdf.

R. L. Tierney. 2004. "The Scope of Aristotle's Essentialism in the Posterior Analytics," Journal of the History of Philosophy 42 (1): 1-20.

M. V. Wedin. 2000. Aristotle's Theory of Substance (Oxford: Oxford University Press).

C. Witt. 1989. Substance and Essence in Aristotle (Ithaca and London: Cornell University Press).

J. Yu. 2003. The Structure of Being in Aristotle's Metaphysics (Dordrecht: Kluwer). 